\title{
Systematic review of fit note use for workers in the UK
}

\author{
Sarah Dorrington, ${ }^{1,2}$ Emmert Roberts, ${ }^{1,2}$ Arnstein Mykletun, ${ }^{3,4,5,6,7}$ Stephani Hatch, ${ }^{1}$ \\ Ira Madan, ${ }^{8}$ Matthew Hotopf ${ }^{1,2}$
}

\begin{abstract}
- Additional material is published online only. To view please visit the journal online (http://dx.doi.org/10.1136/ oemed-2017-104730).
\end{abstract}

${ }^{1}$ Department of Psychological Medicine, Institute of Psychiatry, Psychology and Neuroscience, King's College London, London, UK

${ }^{2}$ South London and Maudsley NHS Foundation Trust, London, UK

${ }^{3}$ Department of Mental Health and Suicide, Norwegian Institute of Public Health, Oslo, Norway

${ }^{4}$ Centre for Work and Mental Health, Nordland Hospital Trust, Bodø, Norway

${ }^{5}$ Research Unit, Directorate of Labour and Welfare, Oslo, Norway

${ }^{6}$ Centre for Research and Education in Forensic Psychiatry and Psychology, Haukeland University Hospital, Bergen, Norway

${ }^{7}$ Department of Community Medicine, University of Tromsø, Tromsø, Norway ${ }^{8}$ Department of Occupational Health, Guy's and St Thomas' NHS Foundation Trust, London, UK

\section{Correspondence to}

Dr Sarah Dorrington,

Department of Psychological

Medicine, Western Education

Centre, Institute of Psychiatry,

Psychology and Neuroscience,

King's College London, London, SE5 9RJ, UK;

sarah.dorrington@kcl.ac.uk

Received 24 August 2017 Revised 23 February 2018 Accepted 9 March 2018 Published Online First 7 May 2018

Check for updates

\footnotetext{
To cite: Dorrington $\mathrm{S}$, Roberts E, Mykletun A, et al. Occup Environ Med 2018:75:530-539.
}

\section{ABSTRACT}

Objectives The fit note, introduced in England, Wales and Scotland in 2010, was designed to change radically the sickness certification process from advising individuals on their inability to work to advising them on what they could do if work could be adapted. Our review aimed to evaluate the following: (1) Is the 'maybe fit' for work option being selected for patients? (2) Are work solutions being recommended? (3) Has the fit note increased return to work? (4) Has the fit note reduced the length of sickness absence? We considered the way in which outcomes vary according to patient demographics including type of health problem.

Methods Studies were identified by a systematic search. We included all studies of any design conducted in the UK with working age adults, aged 16 or over, from 1 April 2010 to 1 Nov 2017. Risk of bias was assessed using a modified Newcastle-Ottawa Scale.

Results Thirteen papers representing seven studies met inclusion criteria. In the largest study, 'maybe fit' for work was recommended in $6.5 \%$ of fit notes delivered by general practitioners (GP; $n=361801$ ) between April 2016 and March 2017. 'Maybe fit' recommendations were made in $8.5 \%-10 \%$ of fit notes received by primary care patients in employment, and in 10\%-32\% of patients seen by GPs trained in the Diploma in Occupational Medicine. 'Maybe fit' was recommended more for women, those with higher socioeconomic status, and for physical, as opposed to psychiatric disorders. The majority of fit notes with the 'maybe fit' option selected included work solutions. There was inconclusive evidence to suggest that the introduction of the fit note has reduced sickness absence among patients in employment.

Conclusions Fit notes represent a major shift in public policy. Our review suggests that they have been incompletely researched and not implemented as intended.

\section{INTRODUCTION}

The impact of long-term sickness absence from employment is usually expressed in financial terms, with an estimated $£ 14$ billion lost to the UK economy every year. ${ }^{1}$ However, it also has devastating consequences for affected individuals and families, leading to social exclusion, widened health inequalities and financial insecurity. ${ }^{2}$ Patterns of sickness absence in the UK have changed considerably over the past few decades. ${ }^{3}$ There has been a decline in sickness certification for musculoskeletal conditions; mental illness has become the leading cause of long-term sickness absence in the UK. ${ }^{4}$ The relationship between sickness absence and health

\section{Key messages}

What is already known about this subject?

- The fit note, introduced in England, Wales and Scotland in 2010, was designed to radically change the sickness certification process from advising on individuals' inability to work to emphasise what they may be able to do if work solutions were made available.

- This is the first systematic review of the literature evaluating the implementation and impact of the fit note.

\section{What are the new findings?}

- Our review has found little quantitative research into the impact of this major policy change. Available research suggests that fit notes have been incompletely researched and not implemented as intended; the results are inconclusive.

- The largest study found that $6.5 \%$ of fit notes had 'maybe fit' recommended. Across all studies, the majority of fit notes with 'maybe fit' recommended included work solutions.

\section{How might this impact on policy or clinical practice in the foreseeable future? \\ - On the basis of available evidence, it is unclear whether fit notes would, if properly implemented, give a desired change for patients. \\ - Evidence suggests that fit note implementation could be improved by legislation which encourages employers to adapt to the needs of patients. Low-cost staggered implementation could be used to evaluate the impact of future policy change on patients.}

status is non-linear-many people with significant disability participate in the workplace. ${ }^{5}$ The lack of a clear correlation between disease severity and sickness absence suggests that sickness absence is not an inevitable consequence of mental or physical illness. $^{67}$

The report by UK government advisor, Dame Carol Black, suggested that a contributor to the problem of long-term sickness absence was the process of sick certification by general practitioners (GPs). ${ }^{8}$ In the UK, sickness absence beyond 7 days requires certification, most often delivered by a GP. Black's review recommended the introduction of a 'fit note' (figure 1), a potentially powerful intervention, which was implemented 
in 2010 to replace the sick note in the GP setting, followed secondary care settings. This was based on clear evidence that fitness for work is not a binary decision. ${ }^{9}$ A growing body of research from Nordic countries suggests that the introduction of reduced working hours, known as partial sickness absence, can improve long-term occupational and health outcomes for patients. ${ }^{10}$ Partial sickness absence and similar interventions such as the fit note could be implemented in other countries, particularly in settings with welfare systems in place. ${ }^{10}$

The fit note expands the 'fit to work' or 'not fit to work' options, by including a third 'maybe fit' option. In addition to this third option doctors and patients are invited to indicate circumstances under which the patient could work, ${ }^{11}$ and to identify potential 'work solutions', similar to partial sickness absence. These 'work solutions' include a graded return to work, altered hours, amended duties and workplace adaptations. $^{12} 13$ The fit note is designed to enable the GP to be an advisor on work, rather than an adjudicator, ${ }^{14}$ the GP can provide guidance for the patient and the employer. The fit note also has a role in providing evidence of long-term sickness absence in applications for employment and support allowance. Importantly, GP 'maybe fit' advice and work solutions on the fit note do not prevent individuals from obtaining benefits.

Initially, the fit note completely replaced the sick note only in primary care, followed by its introduction in secondary care settings.

\section{Statement of Fitness for Work For social security or Statutory Sick Pay}

Patient's name
I assessed your case on:
and, because of the
following condition(s):

If available, and with your employer's agreement, you may benefit from:

$\square$ a phased return to work altered hours amended duties workplace adaptations

Comments, including functional effects of your condition(s):

6

Figure 1 Fit note. 
To support this major shift in UK policy, the fit note was introduced with a specially designed national educational programme for GPs, distinct from the broader Diploma in Occupational Medicine (DipOccMed) also available to GPs. ${ }^{15}$ The introduction of the fit note coincided with the development of a government-funded 'Fit For Work' (FFW) pilot scheme which delivers general health and work advice to employees, employers and GPs via a website and telephone line; the scheme is currently undergoing major changes due to a lack of uptake. ${ }^{16} 17$ There have been numerous publications guiding GPs, employees and employers on how best to use the fit note. ${ }^{18} 19$ Previous studies have explored the acceptability of fit notes for GPs, employers and patients. ${ }^{20-22}$ A recent UK government white paper published in November 2017, Improving Lives: The Future of Work, Health and Disability, ${ }^{17}$ has drawn attention to the fit note, and raised questions about its future. This is the first systematic review of the literature evaluating the implementation and impact of the fit note.

We aimed to address whether the fit note is meeting its stated aims: (1) Is the 'maybe fit' for work option being selected for patients? (2) Are work solutions being recommended? (3) Has the fit note increased return to work? (4) Has the fit note reduced the length of sickness absence? We consider the way in which outcomes vary according to patient demographics including type of health problem.

\section{METHODS}

\section{Search strategy and inclusion criteria}

The review is reported according to the Preferred Reporting Items for Systematic Reviews and Meta-Analyses (PRISMA) group. ${ }^{23}$ The search strategy can be found in online supplementary files 1 and 2. We searched Embase, Cochrane CENTRAL, Medline, HMIC, Social Policy and Practice, PubMed and PsycInfo from 1 April 2010 to 1 November 2017. The search terms were 'fitnote(s)' or 'fit note(s)' or 'fit-note(s)'. Studies were included if they were reported in English and the study population was working age adults (16-65) in England, Scotland or Wales. We included any study design that reported one of the following outcomes: (1) the use of 'maybe fit', (2) work solutions on fit notes, (3) changes in return to work, and (4) length of sickness absence after the introduction of the fit note. We excluded qualitative studies and case series.

Two authors (SD and ER) initially assessed the titles and abstracts identified by the search and reviewed the full text of the remaining articles for inclusion. Any discrepancy was resolved by discussion, and where agreement could not be reached a third author $(\mathrm{MH})$ was consulted. All relevant references were checked for additional citations.

\section{Data extraction}

Two authors (SD and ER) extracted the following data from each study using a data extraction proforma (see online supplementary file 3): the first author's last name, publication year, country or region where the study was conducted, study period, sample size, number of participants, funders, whether exclusions were made, effect sizes and 95\% CIs for our outcome variables: 'maybe fit', work solutions, recommended length of sickness absence and return to work.

\section{Quality assessment}

Two authors (SD and ER) used a 10-point quality assessment tool adapted from the Newcastle-Ottawa Scale ${ }^{24}$ for non-randomised studies to assess risk of bias. This scale is used to assess the methodological quality of observational studies and has acceptable validity and reliability. Methodological considerations in each

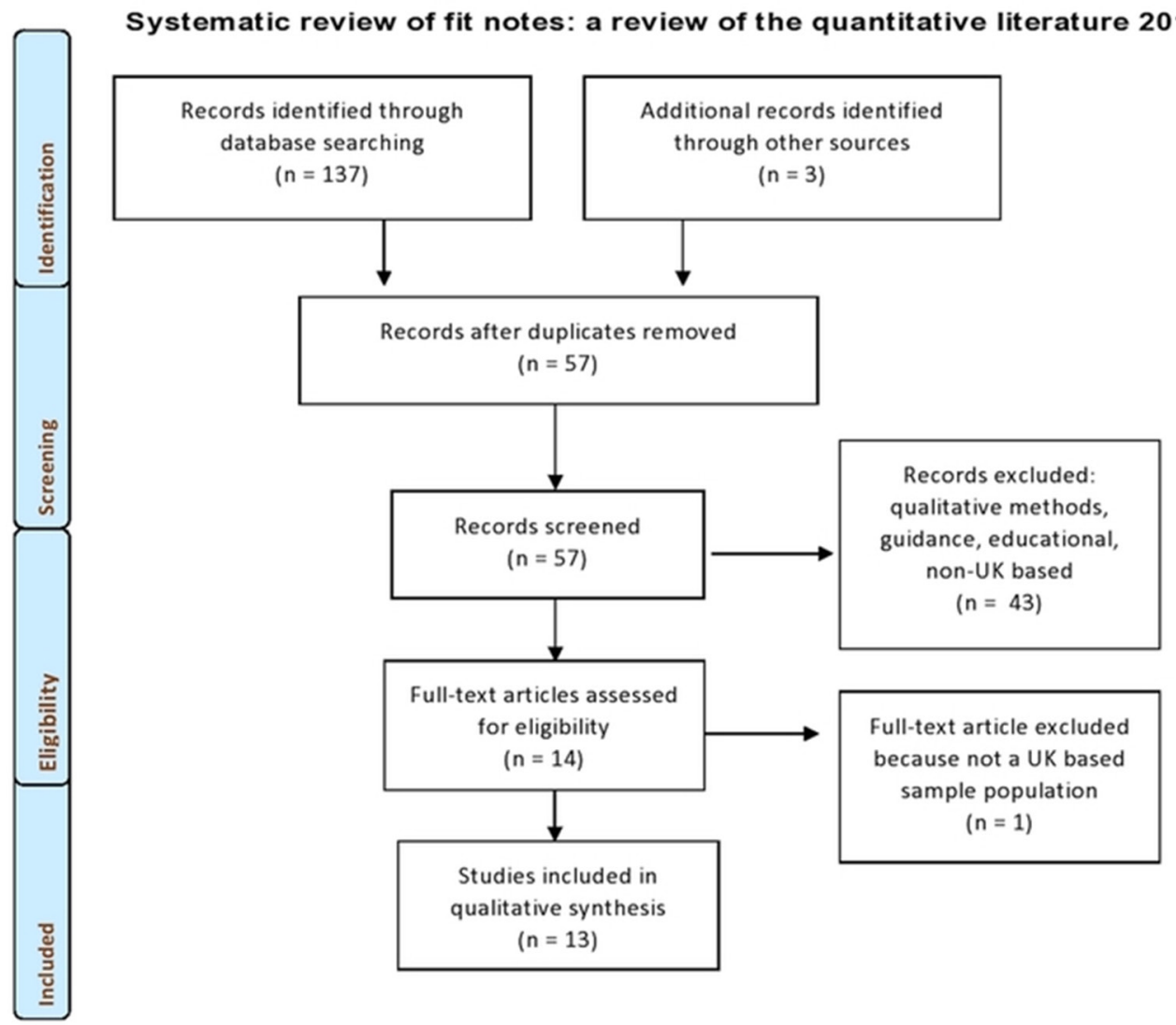

Figure 2 Preferred Reporting Items for Systematic Reviews and Meta-Analyses (PRISMA) diagram. 
cross-sectional study were scored as follows: $0-5$ points for adequate selection of study subjects, $0-2$ points for adequate comparability of study subjects, $0-3$ points for adequate outcome assessment. For longitudinal studies, there were two additional points, one for length of follow-up and one for adequacy of follow-up. Overall study quality for cross-sectional studies was scored as follows: $0-3=$ low quality; $4-7=$ medium quality; $8-10=$ high quality. Longitudinal studies were scored $0-4=$ low quality, $5-8=$ medium quality, $9-12=$ high quality.

\section{RESULTS}

Our initial search returned 137 articles. Fifty-seven papers were original research about fit notes. After applying our inclusion and exclusion criteria we were left with 10 papers. Three additional papers were identified in the grey literature when references were checked for additional citations, making 13 papers in all (see figure 2). ${ }^{25-37}$ Several papers explore different study questions within the same population. The 13 papers identified describe seven studies. The second largest study (study 6 in table 1) was analysed in five different papers, which defined the population in different ways. For example, one paper analysed the entire primary care population ${ }^{32}$ and another restricted the population to employed patients with mental health problems. ${ }^{34}$

We report findings in relation to the type of study population presented: 11 out of the 13 papers explored the use of the fit note in primary care, 1 explored its use by employers ${ }^{30}$ and 1 by employees ${ }^{25}$ (table 1 ). Two of the primary care-based papers analysed the use of the fit note by GPs with a training in the DipOccMed. Seven papers analysed a study funded by the UK government Department of Work and Pensions, three papers were funded by the Institute of Occupational Safety and Health, one was funded by the UK Health and Safety Executive, one was funded by the National Institute of Health Research and the most recent was funded by National Health Service (NHS) Digital.

Three papers compared data from 'before and after' the fit note's introduction ${ }^{27}{ }^{3133}$; the remainder were conducted after the introduction of the fit note. ${ }^{25} 2628-30322^{34-37}$ Four papers were limited to populations of patients in employment. Study sizes ranged from 94 fit notes in the smallest study to 5 million fit notes in the largest. ${ }^{28}{ }^{37}$ See table 1 for more information on study design.

\section{Outcome 1: recommendation of 'maybe fit' for work}

The prevalence of 'maybe fit' use varied from $3.5 \%$ to $32 \%$ of fit notes depending on the population studied (table 2). Several studies analysed demographic variation in 'maybe fit' use; they found variation at both individual and practice level. ${ }^{25} 2731$

\section{All primary care patients}

Two studies analysed fit note use in all primary care patients. In a cross-sectional analysis of GP patients from 68 practices, 'maybe fit' was recommended in $6.4 \%(n=5080)$ of all fit notes. ${ }^{32}$ The same patients could receive multiple fit notes-when this is taken into account, $12 \%$ of all patients receiving fit notes had a 'maybe fit' recommendation at least once $(n=2990) .{ }^{31} 32$ These findings were replicated by NHS Digital: $6.5 \%$ of patients receive a 'maybe fit' recommendation in over 5 million fit notes.

\section{Primary care patients in employment}

Six papers analysed 'maybe fit' use among employed patients. After excluding one study which intentionally oversampled fit notes ${ }^{28}$ we found the prevalence of 'maybe fit' ranged from $7 \%$ to $10 \%$ of all fit notes. Gabbay et al restricted primary care study 6 to include only GP patients who were known to be in employment because employment was recorded by the GP $(32.5 \%$ of fit notes, $\mathrm{n}=25061) .{ }^{33}$ In this population, $8.5 \%$ (2151) of fit notes included a 'maybe fit' recommendation.

Shiels et $a l^{35}$ defined the employed population by excluding patients recorded by their GP as 'not in work' (7\%, $\mathrm{n}=2315$ patients with 3468 discrete episodes). Patient episodes were analysed, rather than individual fit notes. In 91\% $(n=28588)$ of first episodes the GP recommended that the patient should abstain from all work. In the remaining $9 \%$ $(n=2865)$ the episode had concluded with the GP advising that the patient 'may be fit' to work provided adjustments were made to normal working conditions.

Three other papers in our sample analysing fit notes given to patients in employment found the use of 'maybe fit' to be $9 \%-10 \%$ of fit notes; two of these papers analysed the same study data. 252930 The sixth report restricted the population to fit notes for employed patients with mental health problems and found a lower percentage, 7\% $(\mathrm{n}=562)$, of fit notes recommending 'maybe fit'.

\section{GPs with a Dip0ccMed}

Two studies analysed fit notes provided by GPs with a DipOccMed. ${ }^{26} 27$ The DipOccMed is undertaken by medical practitioners who are working part-time in occupational medicine or who have an interest in occupational medicine. It is most frequently taken by GPs who often add to their practice portfolio by providing occupational health services to local companies. Around 4\% of GPs complete the DipOccMed. ${ }^{27}$ The first study included both GPs with DipOccMed delivering the new FFW service, and untrained GPs; fit notes were measured. ${ }^{26}$ The second study included only GPs training or trained in the DipOccMed, and measured cases. ${ }^{27}$ In the first study, overall $10 \%(n=73)$ of all fit notes had 'maybe fit' recommended, ${ }^{26}$ compared with $6.5 \%$ of patients seen by all GPs. ${ }^{37}$ In the population referred to the FFW service, a much higher percentage, $32 \%$, of fit notes had a 'maybe fit' recommendation. ${ }^{26}$ In the second study in which 'maybe fit' was measured by cases, $25 \%$ of cases $(n=209)$ were given 'maybe fit' notes, compared with $12 \%$ of cases seen by all GPs. ${ }^{27} 31$

\section{Additional studies}

Coole et al used a sampling method which intentionally oversampled 'maybe fit' notes. ${ }^{28}$ GPs were asked to record the first 10 'new' fit notes issued to employed patients including a minimum of five 'maybe fit' notes. As expected from this sampling strategy, 'maybe fit' use was over-represented in their sample, $27 \%{ }^{25}$ of all fit notes.

\section{Outcome 2: work solutions: structured and free-text advice on the fit note}

A high percentage of 'maybe fit' notes included advice on work solutions (table 2). ${ }^{25} 2731-34$

\section{Primary care population}

In the primary care population, ${ }^{32}$ eighty-three per cent $(n=4202)$ of 'maybe fit' notes had structured advice, but over $26 \%$ of these included no free-text advice to guide patients and employers. ${ }^{32}$ Among fit notes with structured advice, $42 \%$ indicated amended duties, 37\%a phased return, $22 \%$ altered hours and $10 \%$ workplace adaptations. ${ }^{31}$ 


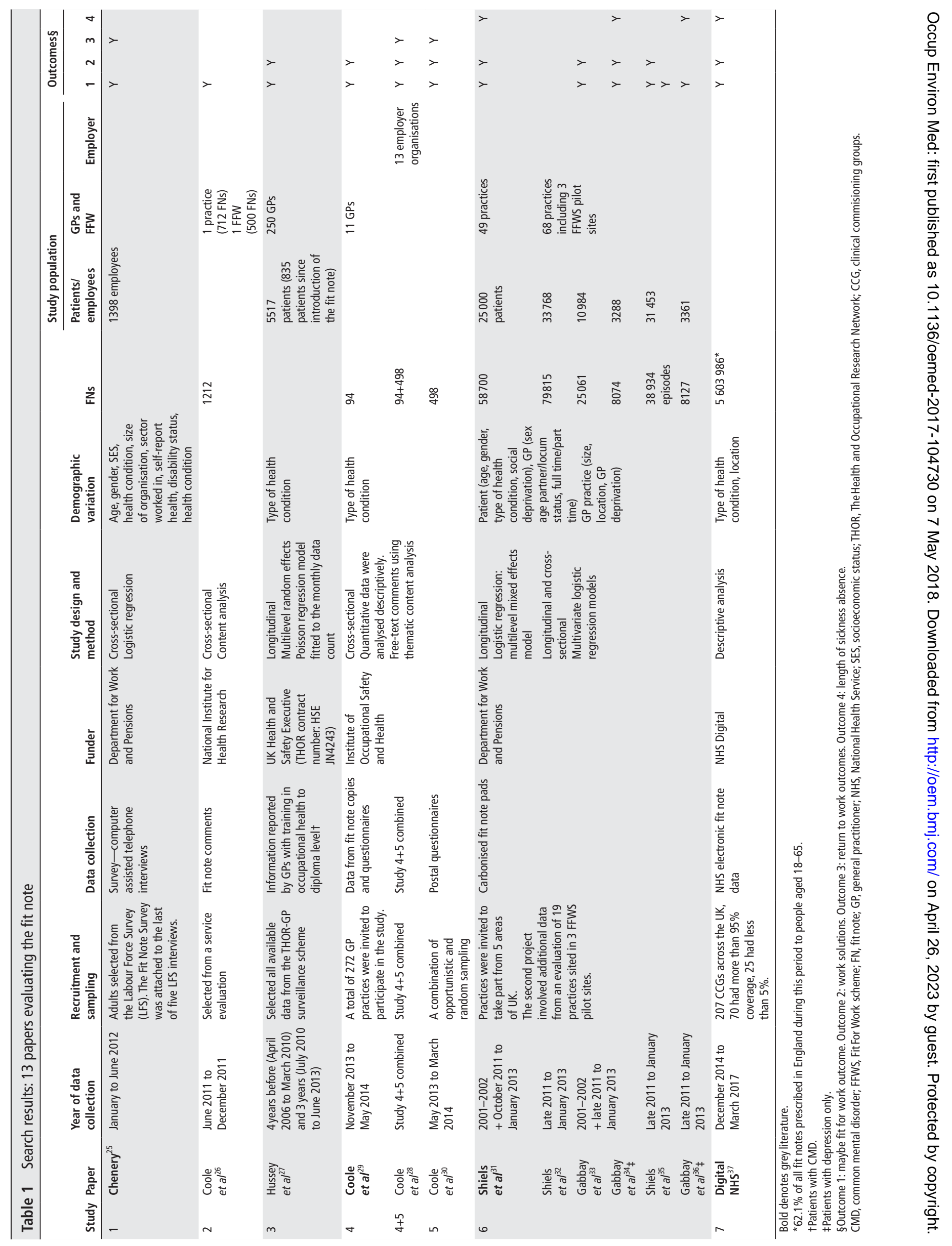


Table 2 Outcomes $1-4$ by population sample

\begin{tabular}{|c|c|c|c|c|c|c|c|}
\hline \multirow[b]{2}{*}{$\begin{array}{l}\text { Population } \\
\text { sample }\end{array}$} & \multirow[b]{2}{*}{ Paper } & \multicolumn{2}{|c|}{ Outcome 1: 'May be fit for' work option selected } & \multicolumn{2}{|c|}{$\begin{array}{l}\text { Outcome 2: work solution: structured and free-text } \\
\text { advice }\end{array}$} & \multirow{2}{*}{$\begin{array}{l}\text { Outcome 3+4: return } \\
\text { to work outcomes } \\
\text { and length of sickness } \\
\text { absence }\end{array}$} & \multirow[b]{2}{*}{$\begin{array}{l}\text { Newcastle-Ottawa Scale } \\
\text { (adapted) }\end{array}$} \\
\hline & & By fit note & By case* & On all fit notes & $\begin{array}{l}\text { On fit notes with 'may be } \\
\text { fit' selected }\end{array}$ & & \\
\hline \multirow[t]{4}{*}{ All GP patients } & Shiels et a ${ }^{31}$ & $6 \%(3670 / 58700)$ & $12 \%(2990 / 25000)$ & & $\begin{array}{l}82 \% \text { structured advice } \\
7 \%(273) \text { no structured or } \\
\text { free-text advice } \\
64 \% \text { free-text advice } \\
10 \%(376) \text { free-text advice } \\
\text { only }\end{array}$ & $\begin{array}{l}\text { Reduction in certifications } \\
\text { length among those }>4 \\
\text { weeks and }>12 \text { weeks in } \\
3 / 7 \text { individual practices but } \\
\text { not overallt } \dagger\end{array}$ & High 12/12 \\
\hline & Shiels et a $\beta^{32}$ & $6.4 \%(5080 / 79375)$ & & & $\begin{array}{l}83 \% \text { of MBF notes had } \\
\text { some structured advice } \\
\text { given. Over } 26 \% \text { had } \\
\text { structured advice but no } \\
\text { free-text advice. }\end{array}$ & & High 10/10 \\
\hline & Gabbay et al $\ddagger^{36}$ & $\begin{array}{l}3.5 \% \text { ( } 286 / 8127) \text { of fit } \\
\text { notes for depression }\end{array}$ & & & & $\begin{array}{l}17 \% \text { of maybe fit notes and } \\
35 \% \text { of all fit notes were for } \\
\text { over } 4 \text { weeks }\end{array}$ & High 10/10 \\
\hline & Digital $\mathrm{NHS}^{37}$ & $6.5 \%$ (361 801/5 603986$)$ & & & $\begin{array}{l}\text { More than } 80 \% \\
\text { recommended an } \\
\text { adaptation in the } \\
\text { workplace, working hours } \\
\text { or duties. }\end{array}$ & $\begin{array}{l}34 \% \text { of fit notes were } \\
\text { for } 5 \text { weeks or longer in } \\
2016-2017\end{array}$ & High 10/12 \\
\hline \multirow[t]{2}{*}{$\begin{array}{l}\text { Occupational } \\
\text { health-trained } \\
\text { GPs seeing all } \\
\text { GP patients }\end{array}$} & Coole et $a l^{26}$ & $\begin{array}{l}\text { FFWS } 32 \%(160 / 500) \\
\text { GP } 10 \%(73 / 712)\end{array}$ & & & $\begin{array}{l}\text { FFWS: } 98 \% \text { (157) advice of } \\
\text { any type } \\
\text { GPs: } 72 \% \text { (53) advice of } \\
\text { any type }\end{array}$ & & Medium 4/10 \\
\hline & Hussey et $a^{27}$ & & $\begin{array}{l}25 \% \\
(209 / 835) \S\end{array}$ & $\begin{array}{l}16 \%(131 / 835) \S \text { of cases } \\
\text { had structured advice }\end{array}$ & & & Medium 8/12 \\
\hline \multirow[t]{6}{*}{$\begin{array}{l}\text { Employed } \\
\text { patients only }\end{array}$} & Coole et $a l^{28} \dagger$ & $27 \%(25 / 94)$ & & $\begin{array}{l}\text { Free-text comment types: } \\
23 \text { work-related advice } \\
11 \text { functional effects of a } \\
\text { patient's condition } \\
8 \text { information on a health } \\
\text { condition }\end{array}$ & $\begin{array}{l}84 \%(21 / 25) \text { of GP MBF } \\
\text { notes had structured advice. }\end{array}$ & & Medium 4/10 \\
\hline & Coole et $a P^{30} \dagger$ & $10 \%(51 / 498)$ & & & & $42 \%(211 / 498)$ RTW & Medium 5/10 \\
\hline & Chenery $^{25}$ & $\begin{array}{l}9 \% \text { overall ( } 4 \% \text { of first fit } \\
\text { notes, } 19 \% \text { of secondary } \\
\text { fit notes) }\end{array}$ & & & $\begin{array}{l}>78 \% \mathrm{MBF} \text { had structured } \\
\text { advice. }\end{array}$ & $82 \%$ RTW & High $8 / 10$ \\
\hline & Gabbay et $a l^{33}$ & $8.5 \%(2151)$ & & $\begin{array}{l}12 \% \text { (1602) of all sickness } \\
\text { episodes concluded with } \\
\text { MBF and work solutions. } \\
\text { Return to work advice from } \\
\text { the GP was included in: } \\
17 \%(210 / 1205) \text { of sickness } \\
\text { episodes due to a fracture } \\
\text { or other injury } \\
16 \% \text { ( } 295 / 1858) \text { certified } \\
\text { sickness episodes due } \\
\text { to MSK } \\
10 \% \text { (393/3950) of } \\
\text { certified sickness episodes } \\
\text { due to MMMD }\end{array}$ & $\begin{array}{l}44 \% \text { (955) amended duties, } \\
34 \% \text { phased return, } 20 \% \\
\text { altered hours and } 9 \% \\
\text { workplace adaptations }\end{array}$ & $\begin{array}{l}\text { Significant reduction in } \\
\text { sickness episode length } \\
>12 \text { weeks OR } 0.65 \\
(0.58-0.72) \\
\text { MBF predicts shorter } \\
\text { sickness absence for all } \\
\text { patients except those with } \\
\text { mental health problems }\end{array}$ & High $11 / 12$ \\
\hline & Gabbay et $a^{34}$ q & $\begin{array}{l}7 \%(562 / 8074) \text { of fit notes } \\
\text { for employed patients } \\
\text { with CMD }\end{array}$ & & & $\begin{array}{l}57 \%(318) \text { phased return, } \\
30 \%(169) \text { altered hours, } \\
23 \%(129) \text { amended } \\
\text { duties, } 8 \%(43) \text {, workplace } \\
\text { adaptations. } 57 \%(321) \\
\text { some written advice. }\end{array}$ & & High 9/10 \\
\hline & Shiels et $a^{\beta 5}$ & $\begin{array}{l}\text { 9\% (2865) of first fit note } \\
\text { episodes ended with a } \\
\text { MBF note }\end{array}$ & & & & & High $9 / 10$ \\
\hline
\end{tabular}

\section{Primary care patients in employment}

Among the $8.5 \%$ of employed patients recommended a fit note, a large proportion had work solutions recommended: 44\% amended duties, 34\% phased return, 20\% altered hours and 9\% workplace adaptations. In the study which oversampled fit notes with 'maybe fit' recommended, of the 98 fit notes received, free-text comments were divided into three groups: 23 fit notes had 'work-related advice', 11 had comments on the 'functional effects of a patient's condition' and 8 had 'additional information on a health condition'. ${ }^{27}$

\section{GPs with a DipOccMed}

Among patients seen by occupational health-trained GPs, 16\% of cases had fit notes with both 'may be fit' and structured advice. ${ }^{27}$ In a small study of GPs with DipOccMed, structured or unstructured advice was given on $72 \%$ of 'maybe fit' notes in primary care and $98 \%$ of 'maybe fit' notes in the FFW service. ${ }^{26}$ GPs with a DipOccMed were more likely to recommend 'maybe fit' and to give advice on work solutions when seeing patients referred to the FFW service. ${ }^{26} 27$ 


\section{Outcome 3: return to work outcomes}

Return to work following fit note use was examined in two cross-sectional studies of employers and employees, both contain patients in employment. In these studies, $42 \%-82 \%$ of people returned to work after a fit note. ${ }^{2530}$ The results were not compared with return to work before the introduction of the fit note, only to 'not fit' notes: Coole et al found that more than $80 \%$ (44) of employees returned to work after the expiry date of a 'may be fit' note compared with 43\% (167) of those issued with a 'not fit' note. ${ }^{30}$

\section{Outcome 4: change in duration of sickness absence}

The most recent study found that between 2016 and 2017, a third of fit notes $(33.6 \%)$ were for 5 weeks or longer. ${ }^{37}$ Two 'before and after' papers analysed the same cohort of GPs and patients from 2001 to 2002 and 2011-2013 to explore changes in length of sickness absence, before and after the introduction of the fit note. ${ }^{3133}$ Shiels $e{ }^{3} l^{31}$ found no change in long-term sickness absence across all seven GP practices. Gabbay et $a l^{33}$ studied the same population, restricted to the $31 \%$ of patients whose occupation was recorded by the GP, with the aim of identifying a patient population in employment. These selected patients were pooled in a multilevel logistic regression analysis, which found a reduction in the risk of a long-term (over 12 weeks) certified sickness episode (OR $0.65(0.58-0.72))^{33}$ for patients who had occupational information recorded by their GP.

The use of 'maybe fit' advice was associated with shorter time off work recommended by GPs. ${ }^{31}$ When the population recorded as 'not in work' was excluded from the primary care population, patients whose initial episode ended with a 'may be fit' note had a reduced rate of follow-up fit note with the same diagnosis as their first fit note (incidence rate ratio $(I R R)=0.72$, 95\% CI 0.63 to 0.81$)^{34}$

Employed patients who had received 'may be fit' advice on a fit note at the end of their first episode were significantly less likely to have another episode of sickness absence within the study period. ${ }^{35}$ However, in the report of patients in employment with a mental disorder on their fit note, 'maybe fit' episodes were longer than episodes where no return to work advice was offered (median weeks 5.5 weeks compared with 4 weeks, $\mathrm{p}<0.001){ }^{34}$ Longer duration of these 'maybe fit' episodes was statistically significant for both stress (5.4 vs 3.0 weeks, $\mathrm{p}<0.001)$ and bereavement ( 4.2 vs 2.1 weeks, $\mathrm{p}<0.001) .{ }^{34}$

\section{Demographic variation}

Most likely to present for a fit note

In the general primary care population fit notes were most frequently given to women $(56 \%)$ and patients with mental and behavioural disorders (31\%). ${ }^{37}$ In the employed population the pattern was similar, patients most likely to present for a fit note were women, patients with mental health problems, people working in public sector and semiroutine or routine employment, and people with a Disability Discrimination Act disability. ${ }^{25}$

\section{Most likely to receive a 'maybe fit' note}

'Maybe fit' use varied from practices, with a range of 1\%-15\% of fit notes given across 68 practices. ${ }^{31}$ Patient variables associated with receiving a 'maybe fit' note were female sex (OR 1.09 (95\% CI 1.01 to 1.21)), lower deprivation (defined by index of multiple deprivation ${ }^{38}$ ) (more deprived OR 0.86 (95\% CI 0.73 to 0.94$)$ ) and having a physical as opposed to a mental disorder (OR 1.69 (95\% CI 1.58 to 1.81$)$ ). ${ }^{32}$ Only $3.5 \%$ of fit notes given to patients for depression had a 'maybe fit' recommendation, compared with $6.5 \%$ of all fit notes. ${ }^{3637}$ In a study of GPs with a DipOccMed, patients with mental health problems were also less likely to receive 'maybe fit' than patients with physical health problems. $^{27}$

\section{Least likely to receive advice on work adjustments}

A study of GPs training in the DipOccMed found that patients with mental health problems were least likely to receive a structured workplace adjustment: $6 \%$ of cases compared with $21 \%$ musculoskeletal and 23\% of other cases. ${ }^{27}$ 'Maybe fit' notes issued to patients with a mild to moderate mental health disorder had a lower than average proportion $(37 \%)$ of additional written advice from the GP. ${ }^{31}$ However, a study which analysed only employed patients with a fit note for common mental disorders (CMD) found that although only $7 \%$ of employed patients with CMD had a 'maybe fit' recommendation, of those patients $57 \%$ had phased return recommended, 30\% altered hours, 23\% amended work duties, $8 \%$ workplace adaptation and $57 \%$ had some written advice. This suggests that once employed patients with a mental health problem are recommended 'maybe fit', work solutions are recommended. ${ }^{34}$

\section{Least likely to return to work or longer sickness absence}

Gabbay et al found that over 35\% (8127/3361) fit notes issued to patients for depression were over 4 weeks in duration. Predictors of having over 4 weeks' sickness absence recommended was associated with having previous fit notes for depression, not having 'maybe fit' advice on the fit note, being older, living in a deprived neighbourhood and having higher practice deprivation status. Fit notes for depression issued by female GPs to female patients were less likely to be long term. Other GP factors were not significant predictors of a long-term fit note. ${ }^{36}$

The rate of GPs issuing workplace adjustment advice in the occupational health-trained group increased consistently $(I R R=1.12)$ in all diagnoses except mental ill health, which indicated a decrease over the 3 years of $12 \%$ per year. ${ }^{27}$

\section{Quality assessment}

Using the Newcastle-Ottawa Scale to assess risk of bias in each data source (see online supplementary file 4) we found six papers from the same study were high quality ${ }^{31-35}$ (table 3). Of the remaining studies five were medium quality $^{25-28} 30$ and two were high quality. ${ }^{37}$ Several study designs were mixed methods, their quality score reflects the quantitative section of these papers and is not representative of their qualitative methods. ${ }^{262830}$ The main limitations in medium-quality studies were low sample size, non-respondents and the representativeness of sample. Two studies defined the primary care population according to employment status and benefit receipt based on GP records, which are known for poor recording of employment-related variables. ${ }^{34} 35$ We could not test for publication bias due to the limited number of studies in each population: primary care patients, employed patients and patients seen by GPs trained in the DipOccMed.

\section{DISCUSSION}

The 'maybe fit' option is recommended in only a small minority of patients who receive fit notes in UK primary care. ${ }^{25} 2731-35$ Wide variation in practice in the use of 'maybe fit' is seen between GP practices and according to GP training and setting. ${ }^{25-35}$ The highest use of 'maybe fit' and advice on work solutions is by GPs trained in the DipOccMed. 
Table 3 Study quality assessed by the Newcastle-Ottawa Scale

\begin{tabular}{|c|c|c|c|c|c|c|c|c|c|c|c|c|}
\hline & & $\begin{array}{l}\text { Representativeness } \\
\text { of sample }\end{array}$ & Sample size & $\begin{array}{l}\text { Non- } \\
\text { respondents }\end{array}$ & $\begin{array}{l}\text { Ascertainment of } \\
\text { exposure }\end{array}$ & Comparability & Outcome & $\begin{array}{l}\text { Statistical } \\
\text { test }\end{array}$ & $\begin{array}{l}\text { Length of } \\
\text { follow-up }\end{array}$ & $\begin{array}{l}\text { Adequacy of } \\
\text { follow-up }\end{array}$ & Tota & \\
\hline Study & Paper & $0-2$ & $0-1$ & $0-1$ & $0-1$ & $0-2$ & $0-2$ & $0-1$ & $0-1$ & $0-1$ & 10 & 12 \\
\hline 1 & Chenery ${ }^{25}$ & 1 & 1 & 1 & 1 & 2 & 1 & 1 & - & - & 8 & - \\
\hline 2 & Coole et $a^{26}$ & 1 & 0 & 0 & 1 & 0 & 2 & 0 & - & - & 4 & - \\
\hline 3 & Hussey et $a^{27}$ & 1 & 1 & 0 & 1 & 1 & 2 & 1 & & & & \\
\hline 4 & Coole et al GPs ${ }^{* 28}$ & 1 & 0 & 0 & 1 & 0 & 2 & 0 & - & - & 4 & - \\
\hline 5 & Coole et al RTW $* 30$ & 1 & 1 & 0 & 1 & 0 & 2 & 0 & - & - & 5 & - \\
\hline \multirow[t]{6}{*}{6} & Shiels et $a^{\beta 1}$ & 2 & 1 & 1 & 1 & 2 & 2 & 1 & 1 & 1 & - & 12 \\
\hline & Shiels et $a^{\beta 2}$ & 2 & 1 & 1 & 1 & 2 & 2 & 1 & - & - & 10 & - \\
\hline & Gabbay et $a^{\beta 3}$ & 1 & 1 & 1 & 1 & 2 & 2 & 1 & 1 & 1 & - & 11 \\
\hline & Gabbay et $a \beta^{34}$ & 1 & 1 & 1 & 1 & 2 & 2 & 1 & - & - & 9 & \\
\hline & Shiels et $\left.a\right|^{35}$ & 1 & 1 & 1 & 1 & 2 & 2 & 1 & - & - & 9 & - \\
\hline & Gabbay et $a^{\beta 6}$ & 2 & 1 & 1 & 1 & 2 & 2 & 1 & - & - & 10 & - \\
\hline 7 & Digital $\mathrm{NHS}^{37}$ & 2 & 1 & 0 & 1 & 2 & 2 & 0 & 1 & 1 & - & 10 \\
\hline
\end{tabular}

Patients who are more deprived and have a mental disorder are most likely to present for a fit note and least likely to receive a 'maybe fit' recommendation. ${ }^{27}$ Among patients who receive a 'maybe fit' recommendation, the majority are given further advice on adaptations to the workplace. ${ }^{252731-34}$ The low proportion of individuals receiving 'maybe fit' suggests that there are some who would be eligible for this advice who do not receive it. Why might this be? Qualitative research into the acceptability of the fit note describes obstacles to 'maybe fit' note implementation, including insufficient communication and understanding between the triad of employee, GP and employer. ${ }^{22}$ The second white paper from the Health at Work Policy Unit argues that shared knowledge and decision-making could improve occupational support for patients, particularly patients with fluctuating chronic conditions. 153940

Stigma continues to be a problem for patients, who report concerns about disclosure of health status on a fit note, which will be seen by their employer. ${ }^{94-43}$ Some GPs seem apprehensive about the impact discussing work-related issues may have on their relationship with patients, and are sceptical about whether the fit note will have any positive impact. ${ }^{44-47}$ GPs report concerns about the limits to their expertise in occupational health and their understanding of patients' employment. ${ }^{4648} 49$ Therefore, there are significant barriers in implementation. However, these concerns from GPs are amenable to training: GPs who receive some form of work and health training have more positive attitudes to patients' returning to work and to the fit note. ${ }^{50}$ The National Education Programme implemented in 2009 to support the introduction of the fit note, addressed both knowledge and skills for the management of the health and work consultation. The 3-hour interactive workshops increased GP confidence and led to GPs giving higher priority to consultations involving discussions around sickness absence. ${ }^{15} 51$ The evidence reviewed here indicates that more in-depth training in the DipOccMed impacts on the use of 'maybe fit' certification. ${ }^{27}$ Research suggests that a new model of case-specific colleague guidance may also help GPs manage the most challenging sickness absence cases. ${ }^{52}$ There is evidence that training to support use of the fit note by other healthcare professionals is also effective. ${ }^{53}$ Acceptability of the fit note among employers in the UK is high, with many reporting that the fit note had been useful in planning the patient's return to work and modifying their jobs. ${ }^{55-57}$

The motivation behind the introduction of the fit note was to reduce unnecessary sickness absence and improve return to work rates, thereby avoiding the individual and societal costs of long-term sickness absence. The evidence we have reviewed about the impact of the fit note on these outcomes is sketchy. While there is some evidence from before and after studies that the introduction of the fit note reduced sickness absence among patients in employment, ${ }^{27} 3233$ return to work outcomes have not been evaluated against the sick note. ${ }^{2530}$ These data are from observational studies, and it is impossible to know whether the fit note or other unrelated secular changes are responsible for the observed differences. The results are therefore inconclusive-they support the possibility of a favourable impact, but do not allow more definite inferences to be drawn.

There is evidence from other countries supporting a model similar to the fit note. Partial sickness absence was introduced in Norway in 2004 and in Finland in 2007. Like the fit note, it introduces a third option of reduced working hours instead of the binary 'fit for work' versus 'not fit for work'. In contrast to the fit note, partial sickness absence legislation places the burden formally on the employer to adapt to the patient; the employer is expected to pay a salary for the hours the employee is at work and is reimbursed for time that the employee is not working. ${ }^{10}$ In Finland, the use of partial sick leave is voluntary for the individual, in both Finland and Norway the employer is only able to decline if the work arrangements needed at the workplace are not feasible. ${ }^{58}$

Partial sickness absence faces similar challenges to the fit note, yet it has been introduced successfully in Nordic countries and is an effective way to improve return to work. ${ }^{10} 5859$ Demographic variation in use of partial sickness absence is similar to 'maybe fit' use: women, older patients and patients with a slightly higher education and higher earnings prior to the absence spell are more likely to receive partial sickness absence. In Finland, partial sick leave reduced the decline in work participation in patients, especially among those aged 45-65 and in patients with mental disorders. ${ }^{58} 59$

Partial sickness absence was implemented with a change in law demanding adjustments at the workplace to facilitate parttime work. By contrast, the UK fit note is a weaker instrument because there is no legislation to encourage employers directly to put recommended work solutions in place for the employee. $^{58}$

\section{Strengths and limitations}

We used a robust search strategy and adhered to PRISMA guidelines; however, it is not possible to rule out publication biases, 
particularly from analyses reported in the grey literature. We avoided summarising the results in a meta-analysis because the numbers of studies in each category were small, and in some cases papers drew from the same study population. While the formal assessment of quality did not unearth significant problems, the studies were generally limited by their reliance on routine and incomplete data—such as patients' employment status—and the fact that they were universally observational in nature. Ideally, there would have been cluster randomised trials or at least phased introductions using stepped wedge designs to allow the impact of the introduction of fit notes to be understood.

\section{CONCLUSION}

The fit note represents a major shift in policy in an area of urgent public interest. It is therefore remarkable how little published research there is on fit notes. The studies we review indicate that it is incompletely implemented, with only a small minority of GPs using the 'maybe fit' recommendation and significant variation in practice. While it may have had an impact on long-term sickness absence among patients in employment, the research to date does not do justice to the scale of the problem the fit note was designed to address. It is not clear whether the current system could be more effective or whether more regulatory support is needed. Evidence from Nordic countries suggests that fit note implementation could be improved by legislation to encourage employers to adapt to the needs of patients. Low-cost staggered implementation could be used to evaluate the impact of future policy change on patients.

Contributors The authors jointly conceived the study question and designed the review. SD and ER conducted the review. SD, SH, IM and MH planned the review. SD and ER assessed the titles and abstracts identified by the search and reviewed the full text of the remaining articles for inclusion. Any discrepancy was resolved by discussion, and where agreement could not be reached MH was consulted. SD drafted the text, which was commented on by ER, SH, IM, AM and MH.

Funding SD is funded by the Donald Dean Fellowship in Occupational Mental Health from the Royal College of Psychiatrists. This paper represents independent research in part funded by the National Institute for Health Research (NIHR) Biomedical Research Centre at South London and Maudsley NHS Foundation Trust King's College London and the Royal College of Psychiatrists.

Disclaimer The views expressed are those of the author(s) and not necessarily those of the NHS, the NIHR, the Department of Health, or the Royal College of Psychiatrists.

\section{Competing interests None declared.}

\section{Patient consent Not required.}

Provenance and peer review Not commissioned; externally peer reviewed.

(c) Article author(s) (or their employer(s) unless otherwise stated in the text of the article) 2018. All rights reserved. No commercial use is permitted unless otherwise expressly granted.

\section{REFERENCES}

1 CBI. Healthy returns? CBI/Pfizer absence and workplace health survey. London: CBI, 2011

2 Henderson M, Clark C, Stansfeld S, et al. A lifecourse approach to long-term sickness absence--a cohort study. PLoS One 2012;7:e36645.

3 Wynne-Jones G, Dunn KM. Has there been a change in the rates of UK sickness certification for back pain over time? An examination of historical data from 2000 to 2010. BMJ Open 2016;6:e009634.

4 Henderson M, Harvey SB, Overland S, et al. Work and common psychiatric disorders. I R Soc Med 2011;104:198-207.

5 Dame P, Davies SC. Annual Report of the Chief Medical Officer. Public Mental Health Priorities: Investing in the Evidence, 2013.

6 Boot CR, Vercoulen JH, van der Gulden JW, et al. Predictors of changes in sick leave in workers with asthma: a follow-up study. Int Arch Occup Environ Health 2005;78:633-40.

7 Fleten $\mathrm{N}$, Johnsen $\mathrm{R}$, Førde $\mathrm{OH}$. Length of sick leave - why not ask the sick-listed? Sick-listed individuals predict their length of sick leave more accurately than professionals. BMC Public Health 2004;4:46.
8 Black C. Dame Carol Black's Review of the health of Britain's working age population: working for a healthier tomorrow. London: TSO, 2008.

9 Wainwright $E$, Wainwright $D$, Keogh $E$, et al. The social negotiation of fitness for work: tensions in doctor-patient relationships over medical certification of chronic pain. Health 2015;19:17-33

10 Markussen S, Mykletun A, Røed K. The case for presenteeism - Evidence from Norway's sickness insurance program. J Public Econ 2012;96:959-72.

11 Gabbay MB. Electronic fit notes: sickness certification in the new decade. Br J Gen Pract 2010;60:235-6.

12 Waddell G, Burton AK, Kendall N. Vocational rehabilitation: what works, for whom, and when? Great Britain: TSO, 2008:307.

13 Department for Work and Pensions. Health at work- an independent review of sickness absence Dame Carol Black and David Frost CBE. Great Britain: Department for Work and Pensions, 2011.

14 Byng R, Wheat $\mathrm{H}$, Barnes RK. Fit for work? How GPs' decisions about fitness to work can improve health. Br J Gen Pract 2015:65:338-9.

15 Cohen D, Khan S, Allen J, et al. Shifting attitudes: the National Education Programme for work and health. Occup Med 2012:62:371-4

16 DWP. Fit For Work. 2014 https://www.gov.uk/government/uploads/system/uploads/ attachment_data/file/362480/fit-for-work.pdf

17 Department for Work and Pensions DoH. Improving Lives: The Future of Work, Health and Disability. Britain: Department for Work and Pensions, 2017.

18 Thornhill S, Williams N, Eplett L. Completion of the statement of fitness for work: Concise guidance. Clinical Medicine. Journal of the Royal College of Physicians of London 2012;12:63-6.

19 DWP. Fit For Work Guidance for Employers. London: Department for Work and Pensions.

20 Coole C, Nouri F, Potgieter I, et al. Recommendations to facilitate the ideal fit note: are they achievable in practice? BMC Fam Pract 2015;16:138.

21 Ranka S, Parker G. Use of published sickness absence guidelines by human resources professionals. Occup Med 2015;65:107-9.

22 Wainwright $E$, Wainwright $D$, Keogh E, et al. Fit for purpose? Using the fit note with patients with chronic pain: a qualitative study. British Journal of General Practice 2011;61:794-800.

23 Moher D, Shamseer L, Clarke M, et al. PRISMA-P Group. Preferred reporting items for systematic review and meta-analysis protocols (PRISMA-P) 2015 statement. Syst Rev 2015:4:1-9.

24 Herzog R, Álvarez-Pasquin MJ, Díaz C, et al. Are healthcare workers' intentions to vaccinate related to their knowledge, beliefs and attitudes? A systematic review. BMC Public Health 2013;13:154.

25 Chenery V. An evaluation of the statement of fitness for work (fit note): a survey of employees. Sheffield: Department for Work and Pensions, 2013:116.

26 Coole C, Watson PJ, Thomson L, et al. How do GPs complete fit note comments? Occup Med 2013;63:575-8.

27 Hussey L, Money A, Gittins M, et al. Has the fit note reduced general practice sickness certification rates? Occup Med 2015;65:182-9.

28 Coole C, Nouri F, Potgieter I, et al. Completion of fit notes by GPs: a mixed methods study. Perspect Public Health 2015;135:233-42.

29 Coole CD, Watson A, Nouri P, et al. Getting the best from the fit note. Investigating the use of the statement of fitness for work: Report submitted to the IOSH Research Committee, 2015.

30 Coole C, Potgieter I, Nouri F, et al. Return-to-work outcomes and usefulness of actual fit notes received by employers. Fam Pract 2015;32:551-6.

31 Shiels CH, Pollard E, Gabbay M. Evaluation of the statement of fitness for work (fit note): quantitative survey of fit notes. London: Department for Work and Pensions, 2013:95.

32 Shiels C, Gabbay M, Hillage J. Factors associated with prevalence and types of 'may be fit' advice on fit notes: a cross-sectional primary care analysis. $\mathrm{Br} J$ Gen Pract 2014:64:e137-43.

33 Gabbay M, Shiels C, Hillage J. Factors associated with the length of fit note-certified sickness episodes in the UK. Occup Environ Med 2015;72:467-75.

34 Gabbay M, Shiels C, Hillage J. Sickness certification for common mental disorders and GP return-to-work advice. Prim Health Care Res Dev 2016;17:437-47.

35 Shiels C, Gabbay M, Hillage J. Recurrence of sickness absence episodes certified by general practitioners in the UK. Eur J Gen Pract 2016:22:83-90.

36 Gabbay M, Shiels C, Hillage J. The issue of "long-term" fit notes for depression in the UK: patient, GP and general practice variation. J Ment Health 2017:1-8.

37 Digital NHS. Fit notes issued by GP practices: December 2014 - March 2017: experimental statistics. Leeds: Digital NHS, 2017.

38 Britain G, Rose D, Pevalin DJ, et al. The National Statistics Socio-economic Classification: origins, development and use. Basingstoke: Palgrave Macmillan, 2005:112

39 Bevan KSVSS. Fluctuating conditions, fluctuating support. London: The Work Foundation, 2015.

40 Cohen D, Allen J, Rhydderch M, et al. The return to work discussion: a qualitative study of the line manager conversation about return to work and the development of an educational programme. J Rehabil Med 2012;44:677-83. 
41 Black C, Black DC. Dame Carol Black. The report on Attitudes and Barriers to Employment in HIV-positive patients. Occup Med 2010;60:415-7.

42 King R, Murphy R, Wyse A, et al. Irish GP attitudes towards sickness certification and the 'fit note'. Occup Med 2016;66:150-5.

43 Rachman R, Bunce D, Thorley K, et al. Patients' attitudes to sickness certification in general practice. Occup Med 2015;65:485-8.

44 Letrilliart L, Barrau A. Difficulties with the sickness certification process in general practice and possible solutions: a systematic review. Eur J Gen Pract 2012;18:219-28.

45 Hann M, Sibbald B. National Primary Care Research and Development Centre. General practitioners' attitudes towards patients' health and work. Great Britain: Department for Work and Pensions, 2011.

46 Welsh VK, Mallen CD, Wynne-Jones G, et al. Exploration of GPs' views and use of the fit note: a qualitative study in primary care. $\mathrm{Br} J$ Gen Pract 2012;62:363-70.

47 Money A, Hussey L, Thorley K, et al. Work-related sickness absence negotiations: GPs' qualitative perspectives. Br J Gen Pract 2010;60:721-8.

48 Hussey S, Hoddinott P, Wilson P, et al. Sickness certification system in the United Kingdom: qualitative study of views of general practitioners in Scotland. BMJ 2004;328:88

49 Cohen DA, Aylward M, Rollnick S. Inside the fitness for work consultation: a qualitative study. Occup Med 2009;59:347-52.
50 Money A, Hann M, Turner S, et al. The influence of prior training on GPs' attitudes to sickness absence certification post-fit note. Prim Health Care Res Dev 2015; 16:528-39.

51 Cohen D, Khan S, Marfell N. Fit for work? Evaluation of a workshop for rheumatology teams. Occup Med 2016;66:296-9.

52 Nordhagen HP, Harvey SB, Rosvold EO, et al. Case-specific colleaque guidance for general practitioners' management of sickness absence. Occup Med 2017;67:644-7.

53 Alexander VR. Audit of hospital doctor training in sick note certification. Occup Med 2012;62:595-9.

54 Moran A, Mainwaring C, Keane O, et al. Sick Note to Fit Note: one trust's project to improve usage by hospital clinicians. BMJ Open Qual 2018;7:e000220.

55 Kotze E. Employers' views on the fit note. Occup Med 2014:64:577-9.

56 Churchard C. Employers wary of new 'fit note' design. People Management, 2010:9.

57 Wainwright E, Wainwright D, Keogh E, et al. Return to work with chronic pain: employers' and employees' views. Occup Med 2013;63:501-6.

58 Kausto J, Viikari-Juntura E, Virta LJ, et al. Effectiveness of new legislation on partial sickness benefit on work participation: a quasi-experiment in Finland. BMJ Open 2014;4:e06685.

59 Kausto J, Miranda H, Martimo KP, et al. Partial sick leave--review of its use, effects and feasibility in the Nordic countries. Scand J Work Environ Health 2008;34:239-49. 